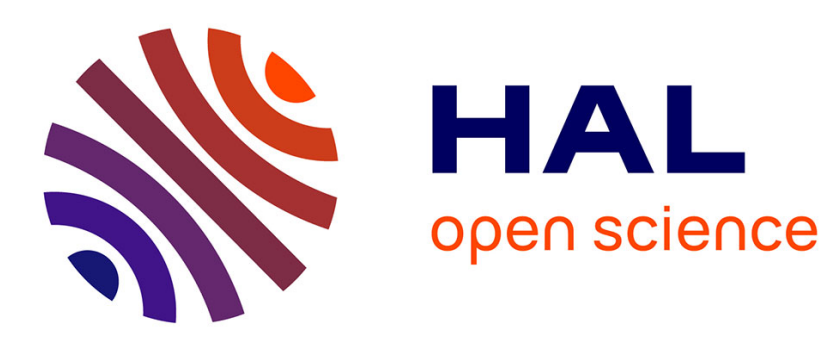

\title{
Variational displacement method for geosynthetically reinforced slope stability analysis II. Global stability
}

Patrick Lemonnier, Abdul-Hamid Soubra, Richard Kastner

\section{To cite this version:}

Patrick Lemonnier, Abdul-Hamid Soubra, Richard Kastner. Variational displacement method for geosynthetically reinforced slope stability analysis II. Global stability. Geotextiles and Geomembranes, 1998, 16 (1), pp.27-44. 10.1016/S0266-1144(98)80001-0 . hal-01007428

\section{HAL Id: hal-01007428 \\ https://hal.science/hal-01007428}

Submitted on 17 Oct 2017

HAL is a multi-disciplinary open access archive for the deposit and dissemination of scientific research documents, whether they are published or not. The documents may come from teaching and research institutions in France or abroad, or from public or private research centers.
L'archive ouverte pluridisciplinaire HAL, est destinée au dépôt et à la diffusion de documents scientifiques de niveau recherche, publiés ou non, émanant des établissements d'enseignement et de recherche français ou étrangers, des laboratoires publics ou privés. 


\title{
Variational displacement method for geosynthetically reinforced slope stability analysis II. Global stability
}

\author{
P. Lemonnier ${ }^{\mathrm{a}}$, A.H. Soubra ${ }^{\mathrm{b}}$, R. Kastner ${ }^{\mathrm{c}}$ \\ a Aalborg University, Dpt. Civil Engineering, Aalborg, Denmark \\ ${ }^{\mathrm{b}}$ Ecole Nationale Supérieure des arts et Industries, Strasbourg, France \\ ' Institut National des Sciences Appliquées, Villeurbanne, France
}

This paper presents the global stability analysis of geosynthetically reinforced slopes. It is a development of the French "displacement method" (Gourc et al., 1986) for geosynthetically reinforced slope stability analysis. The global stability analysis requires the determination of the reinforcement tensions, which is presented in a companion paper (Lemonnier et al., 1998). In this paper, the variational limit equilibrium method, formulated by Baker and Garber (1977) in the case of unreinforced slopes, is applied to the case of reinforced slopes. This variational analysis has shown that the results obtained by Baker and Garber are still valid in the present case.

A parametric study showing the influence of different geometrical parameters on the design is presented and discussed. These results are compared with those of the original "displacement method", in order to show the improvement of the method.

Keywords: Slopes; Reinforced soil; Analysis; Stability

\section{Notation}

$c_{\mathrm{g}} \quad$ adhesion of the soil-geotextile interface

$h_{\mathrm{gi}} \quad$ height of soil above reinforcement $i$

$J \quad$ tensile stiffness of the reinforcements

$L_{i} \quad$ length of reinforcement $i$ 


$\begin{array}{ll}n_{\mathrm{t}} & \text { number of reinforcement sheets } \\ T_{\mathrm{adm}} & \begin{array}{l}\text { admissible tension in the reinforcements } \\ t a_{\mathrm{mini}}\end{array} \\ u_{\mathrm{p}} & \begin{array}{l}\text { minimum rate of linear behaviour of the anchorage zones } \\ \text { minimum soil-geotextile relative displacement which mobilises the ulti- }\end{array} \\ & \text { mate shear stress of the soil-geotextile interface } \tau_{\mathrm{p}} \\ y_{\mathrm{t}} & \begin{array}{l}\text { vertical displacement at the top of the slope } \\ \phi_{\mathrm{g}}\end{array} \\ \tau_{\mathrm{p}} & \begin{array}{l}\text { friction angle characterising the soil-geotextile interface } \\ \text { ultimate shear stress of the soil-geotextile interface. }\end{array}\end{array}$

\section{Introduction}

The stability analysis of geosynthetic reinforced slopes is currently carried out using the conventional limit equilibrium methods modified to account for the reinforcement effect (Jewell, 1982; Rowe and Soderman, 1985; Hird, 1986 and Low et al., 1990). Beside these methods, there is the finite element method (Andrawes et al., 1982) or the methods derived from earth pressure considerations (Steward et al., 1977; Broms, 1978; Collin, 1986 and Bonaparte et al., 1987). The limit equilibrium methods are popular in the practice of geotechnical engineering since they are simple and give relatively accurate solutions. These methods are based on assumptions concerning the shape of the slip surface and the normal stress distribution along this surface. Furthermore, in the case of reinforced slopes, other assumptions are made concerning the determination of the reinforcement tension at the failure surface.

In this paper, the global stability analysis of the reinforced slope is made using a variational approach applied to the limit equilibrium method in order to avoid any assumption concerning the shape of the slip surface and the normal stress distribution along this surface. This analysis is an extension of the variational limit equilibrium method developed by Baker and Garber (1977) in the case of unreinforced slope stability analysis. The assumptions concerning the determination of the reinforcement tensions are examined in detail in a companion paper (Lemonnier et al., 1998) where a theoretical variational approach was developed: It allows this determination by using the concept of the anchored membrane in the neighbourhood of the failure surface, together with a prescribed vertical displacement at the top of the slope to mobilise the tensions in the reinforcements.

In the following sections, one firstly presents the variational limit equilibrium method for the reinforced slope. Secondly, a two-layers geotextile reinforced wall is analysed by the present model. The corresponding results are then presented and discussed. Finally, a combined parametric and comparative study is presented considering the same previous example. This shows the influence of several geometrical parameters on the determination of the safety factor, the reinforcement tensions and their inclinations. These geometrical parameters include (i) the prescribed vertical displacement at wall top, (ii) the elevation of a single sheet in the slope and (iii) the number of reinforcement sheets. The corresponding results are then compared with those obtained from the original "displacement method" in order to show the improvement of the method. 


\section{Present variational analysis}

Fig. 1 shows a slope inclined at $\beta$ with the horizontal direction, reinforced with $n_{\mathrm{t}}$ geosynthetic sheets. Each sheet $i$ has fixed length $L_{i}$ and ordinate $Y_{i}$. In this paper, our aim is to determine the safety factor of the reinforced slope. The present analysis is based on the following assumptions:

- The slope, which has a unit soil weight $\gamma$, height $H$ and mechanical characteristics $\phi$ and $c$, is assumed to be homogeneous and isotropic;

- The safety factor $F_{\mathrm{s}}$ is defined as the minimum value of the ratio $F$ of the maximum shear stress over the mobilised one on the failure surface PR (Fig. 1), along which it is assumed to be constant. Therefore, reduced parameters $c_{\mathrm{r}}=c / F$ and $\operatorname{tg}\left(\phi_{\mathrm{r}}\right)=\operatorname{tg}(\phi) / F$ are considered in the present analysis;

- Only overturning stability analysis is considered in this paper. Therefore, a failure by sliding along a geotextile sheet, for example, is not considered herein;

- The failure surface PR is assumed to pass through the toe of the slope. The case of a failure surface passing below the toe is not considered herein;

- The geotextile reinforcement is assumed to have no flexion rigidity. Thus, the tensions are tangential to the sheets;

- The failure surface is assumed to intersect the geosynthetic sheets at points of maximum tension;

- As in the original "displacement method" (Gourc et al., 1986), a prescribed vertical displacement is assumed to occur at the top of the slope. This displacement induces vertical local displacements for the geotextile sheets in the neighbourhood of the failure surface and thus, allows the mobilisation of tensions in the reinforcements. Then, the concept of the anchored membrane (Gourc et al., 1986) is adopted and the

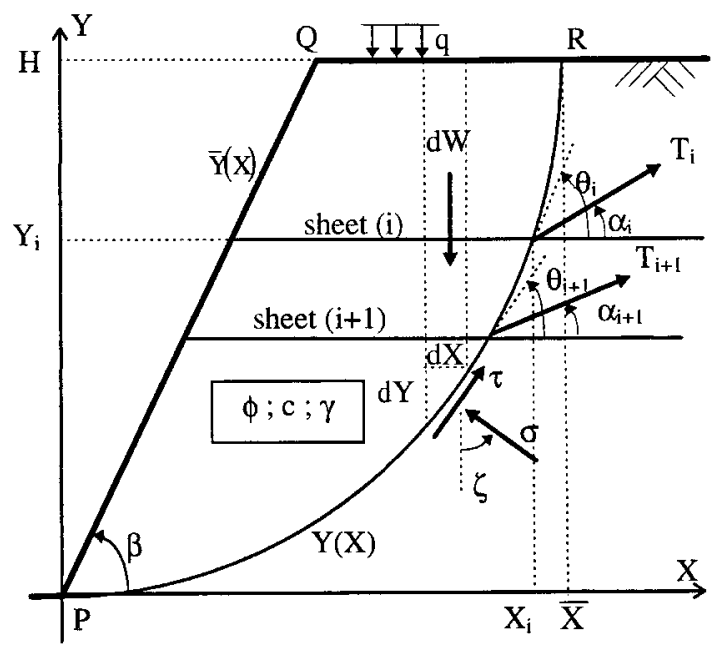

Fig. 1. Geotextile reinforced slope stability analysis. 
reinforcement tensions are determined by means of a minimisation procedure based on a variational analysis (see companion paper).

In the framework of the reinforced slope stability analysis, different assumptions have been made by numerous investigators concerning the shape of the slip surface: (i) planar (Steward et al., 1977; Broms, 1978; Collin, 1986; Bonaparte et al., 1987 and Leshchinsky and Reinschmidt, 1985), (ii) polygonal (Blanchier, 1982; Murray, 1984; Bordairon, 1986; Ratel, 1987 and Schmertmann et al., 1987), (iii) circular (Ingold and Miller, 1984; Ratel, 1987; Bordairon, 1986; Hird, 1986 and Kaniraj, 1994), (iv) logspiral (Anthoine, 1990 and Leshchinsky and Reinschmidt, 1985).

In this paper, the limit equilibrium method is used. This method has already been used by several investigators (Leshchinsky and Reinschmidt, 1985). For the present model, an extension of the variational limit equilibrium method proposed by Baker and Garber (1977) is applied to the reinforced slope (Fig. 1) in order to find the failure surface which gives the minimal value of the safety factor and for which the three limit equilibrium equations of the sliding mass PQR are simultaneously satisfied.

This sliding mass (active zone) is contained between the slope $\bar{Y}(X)$ and the unknown failure surface $Y(X)$. In Fig. 1, the geotextile sheets have been represented horizontally, which is the at rest position. These sheets play their reinforcement role by mobilising a tension force at the intersection with the failure surface. These tension forces are directed from the active to the resistant zone, and are inclined at an angle $\alpha_{i}$ to the horizontal direction (after deformation of the sheets).

The forces acting on the sliding mass are the following (see Fig. 1):

- Sliding mass weight $W$;

- Normal and tangential stress distributions $(\sigma, \tau)$ along the failure surface;

- External load $q$ on the top of the slope;

- Tension $T_{i}$ in each geotextile sheet $i$ at the failure surface.

The limiting equilibrium equations of the sliding mass are given as follows:

$$
\begin{aligned}
& \int_{0}^{\bar{X}}\left(c+\sigma \tan \phi-F . \sigma . Y^{\prime}\right) \mathrm{d} X+F \sum_{i} T_{i} \cos \alpha_{i}=0, \\
& \int_{0}^{X}\left\{Y^{\prime} .(c+\sigma \tan \phi)+F[\sigma-\gamma(\bar{Y}-Y)-q]\right\} \mathrm{d} X+F \sum_{i} T_{i} \sin \alpha_{i}=0, \\
& \int_{0}^{\bar{X}}\left\{(c+\sigma \tan \phi)\left(Y-Y^{\prime} X\right)-F\left[\sigma\left(X+Y Y^{\prime}\right)-[\gamma(\bar{Y}-Y)+q] . X\right]\right\} \mathrm{d} X \\
& \quad+F \sum_{i} T_{i}\left(Y_{i} \cos \alpha_{i}-X_{i} \sin \alpha_{i}\right)=0 .
\end{aligned}
$$

It is assumed that, for each failure line $Y(X)$ considered, each tension $T_{i}$ is determined by the above-mentioned procedure based on the anchored membrane concept (see companion paper). These tensions depend on $Y$ and $Y^{\prime}$, but are independent of $X$. Consequently, the only unknown parameters of the problem are the factor $F$, and functions $Y(X)$ and $\sigma(X)$. 
The terms $F, T_{i}, \alpha_{i}, X_{i}$, and $Y_{i}$ which appear in Eqs. (1.1)-(1.3) under the sum symbols are independent of $X$, thus these terms can be included under the integral symbols. Then, these equations can be expressed as follows:

$$
\begin{aligned}
& \int_{0}^{\bar{X}}\left(c+\sigma \tan \phi-F \cdot \sigma Y^{\prime}+\frac{F}{\bar{X}} \sum_{i} T_{i} \cos \alpha_{i}\right) \mathrm{d} X=0 \\
& \int_{0}^{X}\left\{Y^{\prime}(c+\sigma \tan \phi)+F \cdot[\sigma-\gamma(\bar{Y}-Y)-q]+\frac{F}{\bar{X}} \sum_{i} T_{i} \sin \alpha_{i}\right\} \mathrm{d} X=0, \\
& \int_{0}^{\bar{X}}\left\{(c+\sigma \tan \phi)\left(Y-Y^{\prime} X\right)-F \cdot\left[\sigma\left(X+Y . Y^{\prime}\right)-[\gamma(\bar{Y}-Y)+q] X\right]\right. \\
& \left.+\frac{F}{\bar{X}} \sum_{i} T_{i}\left(Y_{i} \cos \alpha_{i}-X_{i} \sin \alpha_{i}\right)\right\} \mathrm{d} X=0 .
\end{aligned}
$$

The quantity $F$, for which the soil reaches the state of limit equilibrium, depends on the two kinematical and stress functions mentioned above $(Y(X)$ and $\sigma(X)$, respectively). Thus, $F$ may be considered as a functional of two functions termed the safety functional. The safety factor $F_{\mathrm{s}}$ is the minimum value of $F$ :

$$
F_{\mathrm{s}}=\min _{(Y, \sigma)} F\{Y(X) ; \sigma(X)\}=F\left[Y_{\mathrm{e}}(X), \sigma_{\mathrm{e}}(X)\right],
$$

where $Y_{\mathrm{e}}(X)$ and $\sigma_{\mathrm{e}}(X)$ represent, respectively, the extremal kinematical and stress functions.

Consequently, as for the unreinforced slopes (Baker and Garber, 1977), the variational problem can be stated as follows: Find a pair of functions $Y_{\mathrm{e}}(X)$ and $\sigma_{\mathrm{e}}(X)$ which realise the minimum value $F_{\mathrm{s}}$ of the safety functional $F$, and simultaneously verify the three limit equilibrium equations (Eqs. (2.1)-(2.3)).

This safety functional $F$ can be expressed by the ratio of two integrals. Indeed, if $F$ is defined by Eq. (2.1), one obtains:

$$
F=\frac{\int_{0}^{X}(c+\sigma \tan \phi) \mathrm{d} X}{\int_{0}^{X}\left(\sigma Y^{\prime}-\frac{\sum_{i} T_{i} \cos \alpha_{i}}{\bar{X}}\right) \mathrm{d} X} .
$$

Note however that safety functional $F$ has another property which did not occur in the case of unreinforced slopes: The abscissa $\bar{X}$ of the variable endpoint $R$ (see Fig. 1) appears in the integrals of the three limit equilibrium equations.

Following the same variational calculus procedure proposed by Baker and Garber (1977), the initial problem can then be transformed to the following one: Find the minimum value of the functional $G$ defined as follows:

$$
G=\int_{0}^{\bar{X}}\left(c+\sigma \tan \phi-F \sigma Y^{\prime}+\frac{F \sum_{i} T_{i} \cos \alpha_{i}}{\bar{X}}\right) \mathrm{d} X
$$


subject to the condition: $\min G=0$, and to the three following integral constraints:

$$
\begin{aligned}
& \int_{0}^{\bar{X}_{\mathrm{e}}}\left(c+\sigma_{\mathrm{e}} \tan \phi-F_{\mathrm{s}} \sigma_{\mathrm{e}} Y_{\mathrm{e}}^{\prime}+\frac{F_{\mathrm{s}} \sum_{i} T_{i} \cos \alpha_{i}}{\bar{X}_{\mathrm{e}}}\right) \mathrm{d} X=0 \\
& \int_{0}^{\bar{X}_{\mathrm{e}}}\left\{Y_{\mathrm{e}}^{\prime}\left(c+\sigma_{\mathrm{e}} \tan \phi\right)+F_{\mathrm{s}} \cdot\left[\sigma_{\mathrm{e}}-\gamma\left(\bar{Y}-Y_{\mathrm{e}}\right)-q\right]+\frac{F_{\mathrm{s}} \sum_{i} T_{i} \sin \alpha_{i}}{\bar{X}_{\mathrm{e}}}\right\} \mathrm{d} X=0, \\
& \int_{0}^{\bar{X}_{\mathrm{e}}}\left\{\left(c+\sigma_{\mathrm{e}} \tan \phi\right)\left(Y_{\mathrm{e}}-Y_{\mathrm{e}}^{\prime} X\right)-F_{\mathrm{s}} \cdot\left[\sigma_{\mathrm{e}}\left(X+Y_{\mathrm{e}} Y_{\mathrm{e}}^{\prime}\right)-\left[\gamma\left(\bar{Y}-Y_{\mathrm{e}}\right)+q\right] X\right]\right. \\
& \left.\quad+\frac{F_{\mathrm{s}} \sum_{i} T_{i}\left(Y_{i} \cos \alpha_{i}-X_{i} \sin \alpha_{i}\right)}{\bar{X}_{\mathrm{e}}}\right\} \mathrm{d} X=0 .
\end{aligned}
$$

It is to be noted that these three integral constraints depend on the safety factor $F_{\mathrm{s}}$, the extremal functions $Y_{\mathrm{e}}(X)$ and $\sigma_{\mathrm{e}}(X)$, and on the fixed parameter $\bar{X}_{\mathrm{e}}$ which corresponds to the extremal value of the parameter $\bar{X}$.

The solution to this problem may be obtained using the method of Lagrange undetermined multipliers. Thus, instead of considering functional $G$, an auxiliary function $H$ is defined as follows:

$$
H=H_{0}+\lambda_{1} H_{1}+\lambda_{2} H_{2}
$$

where $\lambda_{1}, \lambda_{2}$ are the Lagrange multipliers, and $H_{0}, H_{1}$ and $H_{2}$ are obtained by identification from Eqs. (6.1)-(6.3) respectively.

In the case of the standard problem of the calculus of variations (Petrov, 1968), two Euler equations and a transversality condition for each variable endpoint, have to be written to find the solution. In the present case (dependency on the variable endpoint abscissa $\bar{X}_{\mathrm{e}}$ ), it can be shown (Lemonnier, 1995) that the two Euler equations are identical to the standard case, but the transversality condition is modified.

In applying the first Euler equation to function $\mathrm{H}$, one obtains the same family of critical slip surfaces as for unreinforced slopes, that is the log-spirals of angle $\phi_{\mathrm{r}}$ (see Fig. 2). This suggests that the reinforcement tensions do not affect the shape of the critical slip surface (but certainly its location as it is shown further in Section 4.1).

Note that the log spiral function has a particular property, that the resultant of the elementary forces $(\sigma \mathrm{d} s)$ and $\left(\operatorname{tg} \phi_{\mathrm{r}} \sigma \mathrm{d} s\right)$ passes through the pole of the spiral. Hence, the moment equation about the pole is independent of the stress distribution $\sigma(X)$, and may be used for the determination of the safety factor $F_{s}$. The two remaining equilibrium equations may be satisfied by every $\sigma(X)$ distribution that has two degrees of freedom. Thus, one has to find the critical $\theta_{0}$ and $\theta_{1}$ angles (see Fig. 2) which satisfy the moment equilibrium equation and give the minimum value of the safety functional $F$. This is done by a two-dimensional minimisation procedure of $F$ with respect to $\theta_{0}$ and $\theta_{1}$.

The independence of the safety functional $F$ on the normal stress distribution $\sigma(X)$ may also be shown in another way (Baker and Garber, 1977), considering a special 


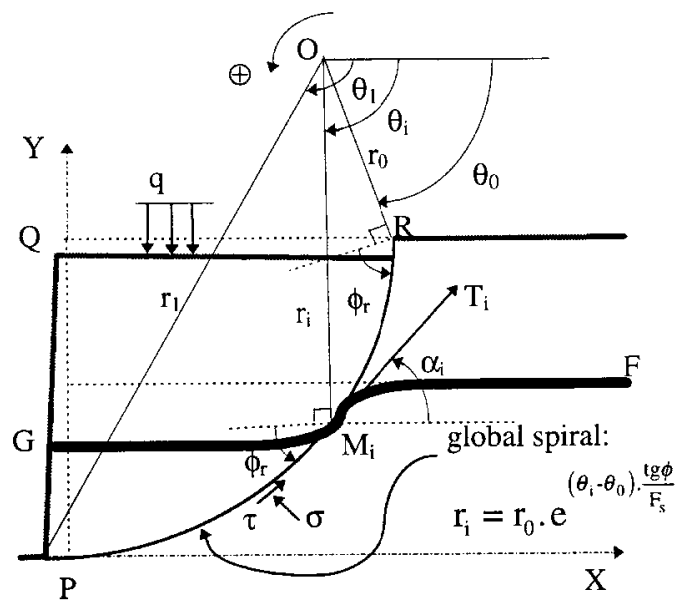

Fig. 2. Global stability of the reinforced slope. Extremal failure surface.

property of this functional. Indeed, for purpose of clarity the function $H$ can be written as follows:

$$
H=m\left(X, \bar{X}_{\mathrm{e}}, Y_{\mathrm{e}}, Y_{\mathrm{e}}^{\prime}\right)+\sigma_{\mathrm{e}} n\left(X, \bar{X}_{\mathrm{e}}, Y_{\mathrm{e}}, Y_{\mathrm{e}}^{\prime}\right) .
$$

This function is linear in $\sigma_{\mathrm{e}}$ and independent of $\sigma_{\mathrm{e}}^{\prime}$. Hence, the application of the first Euler equation gives: $n\left(X, \bar{X}_{\mathrm{e}}, Y_{\mathrm{e}}, Y_{\mathrm{e}}^{\prime}\right)=0$. The substitution of this equation into Eq. (8) shows that $H$ is independent of $\sigma_{\mathrm{e}}$, i.e.

$$
H=m\left(X, \bar{X}_{\mathrm{e}}, Y_{\mathrm{e}}, Y_{\mathrm{e}}^{\prime}\right) .
$$

Furthermore, it has been shown (Baker and Garber, 1977) that the second Euler equation and the transversality condition give the normal stress distribution $\sigma(X)$. Now, this distribution is not necessary for our problem, that is the determination of the safety factor $F_{\mathrm{s}}$ of the reinforced slope. Consequently, it is possible to solve the reinforced slope stability problem by simply minimising the new function $H$ without specifying the normal stress distribution.

\section{Computational procedure}

As shown before, the safety factor $F_{\mathrm{s}}$ of a reinforced slope, is determined considering a $\log$ spiral as the failure surface and by writing the only moment equilibrium equation of forces acting on the sliding mass around the pole of this log spiral. This curve depends on two angular parameters $\theta_{0}$ and $\theta_{1}$ and a factor $F$ (whose minimum is $\left.F_{\mathrm{s}}\right)$. Thus, for each couple $\left(\theta_{0}, \theta_{1}\right)$, there is only one $F$ value which satisfies the moment equilibrium equation, which can be written as follows:

$$
M=M_{0}+\sum_{i=1}^{n_{i}} M_{\mathrm{i}}=0
$$


where $M$ is the sum of moments concerning the reinforced slope, $M_{i}$ is the moment due to tension $T_{i}$ in reinforcement $i$ at point $M_{i}$ (see Fig. 2), and $M_{0}$ the sum of moments concerning the unreinforced slope (i.e. neglecting the reinforcement effects): $M_{0}=M_{\gamma}+M_{\mathrm{q}}+M_{\mathrm{c}}$ where $M_{\gamma}$ the moment due to the weight of the sliding mass; $M_{\mathrm{q}}$ is the moment due to the uniform surcharge on top of the slope; $M_{\mathrm{c}}$ the moment due to cohesion forces in the soil along the failure surface.

Hence, for a given couple $\left(\theta_{0}, \theta_{1}\right)$, one has to determine the unique $F$ value which vanishes the sum $M$. Note that Eq. (9) is implicit and nonlinear in $F$. Thus, a numerical procedure is used to obtain the unique factor $F_{1}$ corresponding to couple $\left(\theta_{0}, \theta_{1}\right)$ and verifying the moment equilibrium equation. That is, Eq. (9) may be written as

$$
f\left(\theta_{0}, \theta_{1}, F_{1}\right)=0 .
$$

Then, the safety factor $F_{\mathrm{s}}$ of the reinforced slope is attained by a two-dimensional minimisation with respect to $\theta_{0}$ and $\theta_{1}$.

Fig. 3 presents the general flow chart which summarises the different steps of this calculation. A computer program, based on this scheme and on the reinforcement tension calculation procedure (cf. companion paper), has been written in FORTRAN.

The first step is the data input. These data (see Fig. 3) may be divided into two groups: The first concerns the soil and the slope, the second concerns the

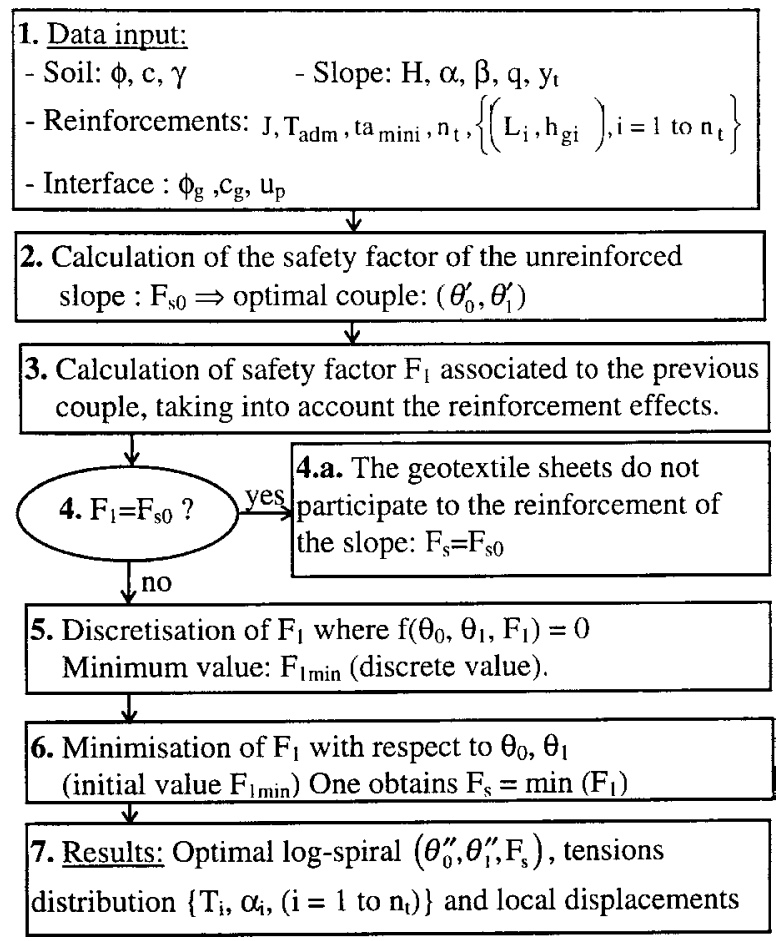

Fig. 3. Flow chart showing the calculation scheme of safety factor $F_{\mathrm{s}}$ of reinforced slopes. 
reinforcements and the soil-geosynthetic interfaces. At this step, the rupture of the reinforcements by excessive strain is checked. The elongation at rupture is usually given by the geosynthetic manufacturers.

Secondly, safety factor $F_{\mathrm{s} 0}$ corresponding to the unreinforced slope is determined. Note that this factor, which is given by Eq. (9) reduced to $M_{0}=0$, is a lower bound of safety factor $F_{\mathrm{s}}$ corresponding to the reinforced slope.

Then, it is interesting to determine factor $F_{1}$ corresponding to couple $\left(\theta_{0}^{\prime}, \theta_{1}^{\prime}\right)$ (the triplet $\left(\theta_{0}^{\prime}, \theta_{1}^{\prime}, F_{\mathrm{s} 0}\right)$ defining the optimal log spiral of the unreinforced slope) and taking into account the effects of the reinforcements (i.e. satisfying the implicit Eq. (10)). Indeed, if one obtains $F_{1}=F_{\mathrm{s} 0}$ for this couple, no other couples $\left(\theta_{0}, \theta_{1}\right)$ give smaller factor $F_{1}$. Then, in this particular case (step 4a, Fig. 3), the reinforcements have no effect on the slope stability, and another configuration of the structure has to be proposed by the designer for an effective reinforcement. For such a case, factor $F_{1}$ corresponding to $\left(\theta_{0}^{\prime}, \theta_{1}^{\prime}\right)$ is greater than $F_{\mathrm{s} 0}$, and so is the safety factor $F_{\mathrm{s}}$ of the reinforced slope.

The numerical procedure to determine $F_{\mathrm{s}}$ is rather complex because the consideration of the reinforcement tensions in the analysis induces discontinuities for function $F_{1}\left(\theta_{0}, \theta_{1}\right)$ which has to be minimised, and function $\mathrm{M}(\mathrm{F})$ whose zero has to be found (cf. Lemonnier, 1995). Hence, a discretisation of the plane $\left(\theta_{0}, \theta_{1}\right)$ is done in order to find a correct starting value for the minimisation process of factor $F_{1}$ (step 5, Fig. 3). Finally, one obtains the optimal log spiral of the reinforced slope: $\left(\theta_{0}^{\prime \prime}, \theta_{1}^{\prime \prime}, F_{\mathrm{s}}\right)$ which gives an evaluation of the stability, together with the position of the failure surface and the associated results of the local stability analysis (reinforcement tensions and relative displacements).

\section{Numerical results}

Fig. 4 shows the configuration of the case study considered in this entire section. It is a vertical wall reinforced by two geosynthetic sheets. The stability analysis of the unreinforced slope gives a safety factor $F_{\mathrm{s} 0}=0.893$. Thus, this slope is unstable and needs to be reinforced.

\subsection{Minimisation of the safety function}

Fig. 4 also shows the results of the present stability analysis. It shows that, by taking into account the reinforcement effects, the safety factor $F_{\mathrm{s}}$ is increased by nearly $65 \%$ and that the failure surface is moved off the face wall. Concerning the critical tensions in the reinforcements, note that (i) they are much smaller than the admissible one $(40 \mathrm{kN} / \mathrm{m})$, (ii) the lowest sheet is more utilized than the other one, and (iii) tension $T_{\mathrm{A} 2}$ is more inclined than $T_{\mathrm{A} 1}$.

All the other results concerning the local behaviour of the geosynthetic sheets are presented in Table 1. The following comments can be made:

- Local displacements $y_{1}$ : Note that $y_{1}$ (sheet 1) $>y_{1}$ (sheet 2). This is due to the assumption that these displacements are induced by the critical failure 


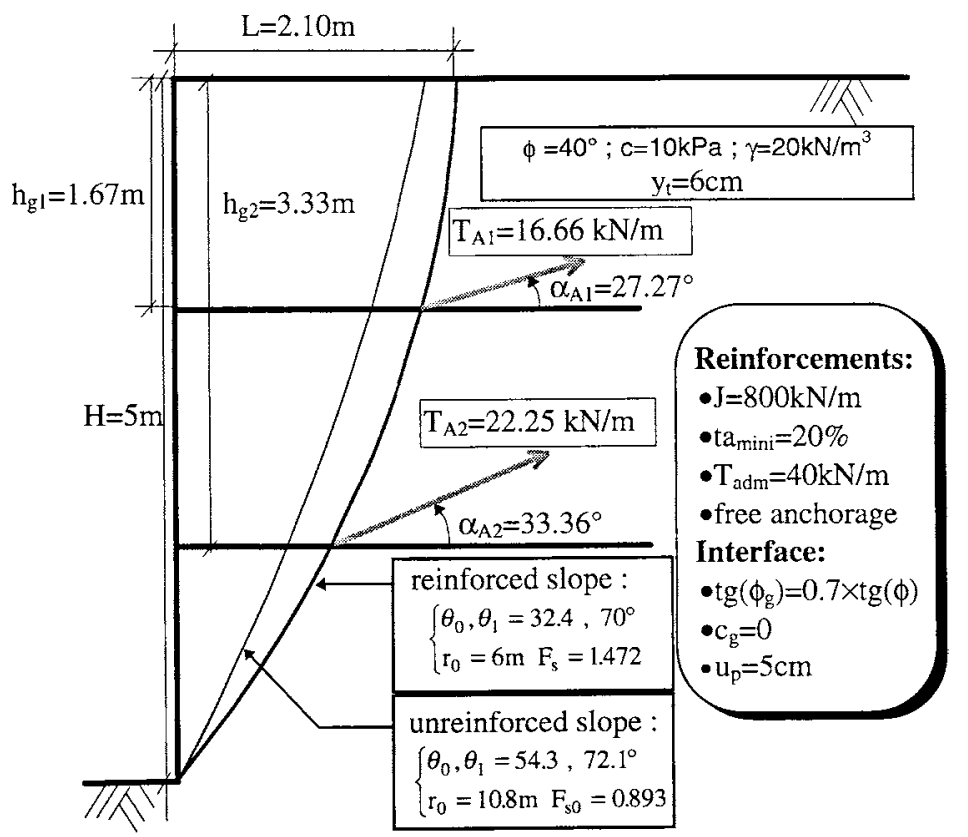

Fig. 4. Configuration of the case study. Results from the present model.

Table 1

Local results from the present model - Case of Fig. 4

Sheet 1

Sheet 2

\begin{tabular}{llcc}
\hline Local displacement & $y_{1}(\mathrm{~mm})$ & 28.9 & 26.5 \\
Rates of linear behaviour & $\operatorname{ta}_{\mathrm{F}}(\%)$ & 100 & 100 \\
& $\operatorname{ta}_{\mathrm{G}}(\%)$ & 100 & 100 \\
Reinforcements lengths & $L_{\mathrm{u}}(\mathrm{m})$ & 3.189 & 3.873 \\
& $L_{\mathrm{d}}(\mathrm{m})$ & 1.811 & 1.127 \\
& $l_{\mathrm{u}}(\mathrm{m})$ & 3.059 & 3.774 \\
& $l_{\mathrm{d}}(\mathrm{m})$ & 1.682 & 1.028 \\
Relative soil-geosynthetic displacements & $u_{\mathrm{F}}(\mathrm{mm})$ & 1.1 & 0.1 \\
& $u_{\mathrm{G}}(\mathrm{mm})$ & 6.1 & 7 \\
& $u_{\mathrm{Bu}}(\mathrm{mm})$ & 10.9 & 9 \\
& $u_{\mathrm{Bd}}(\mathrm{mm})$ & 16.9 & 15.7 \\
Tensions & $\mathrm{T}_{\mathrm{Bu}}(\mathrm{kN} / \mathrm{m})$ & 8.609 & 10.022 \\
& $\mathrm{~T}_{\mathrm{Bd}}(\mathrm{kN} / \mathrm{m})$ & 12.594 & 15.802 \\
Inclinations & $\mathrm{T}_{\mathrm{A}}(\mathrm{kN} / \mathrm{m})$ & 16.656 & 22.246 \\
& $\alpha_{\mathrm{A}}\left({ }^{\circ}\right)$ & 27.267 & 33.362 \\
& $\alpha_{\mathrm{Amax}}\left({ }^{\circ}\right)$ & 73.911 & 61.639
\end{tabular}


surface, which is steeper in the neighbourhood of sheet 1 than that of sheet 2 (see Fig. 4);

- Linear behaviour rates $\operatorname{ta}_{\mathrm{G}}$ and $\mathrm{ta}_{\mathrm{F}}$ : Since the soil-geotextile interface in the four anchorage zones ( 2 for each sheet) behave elastically (i.e. $\operatorname{ta}_{\mathrm{G}}=\mathrm{ta}_{\mathrm{F}}=100 \%$ ), there is no danger concerning the breakage of the reinforcements by a lack of adherence at the soil-geosynthetic interface;

- Reinforcement lengths $L_{\mathrm{u}}, L_{\mathrm{d}}, l_{\mathrm{u}}$ and $l_{\mathrm{d}}$ : It is to be noted that (i) the upstream anchorage zones are longer than the downstream ones (i.e. $L_{\mathrm{u}}>L_{\mathrm{d}}$ ), (ii) the length of the membrane zone is in a proportion of $5.2 \%$ with respect to the total length for sheet 1 (respectively $3.9 \%$ for sheet 2 ). These results are qualitatively in concordance with several experimental observations showing that the shear zone is relatively narrow;

- Relative soil-geosynthetic displacements $u_{\mathrm{F}}, u_{\mathrm{G}}, u_{\mathrm{Bu}}$ and $u_{\mathrm{Bd}}$ : Note that the relative displacements at point $F$ are much smaller than those at point $G$ (see Fig. 2), that is $u_{\mathrm{F}}<u_{\mathrm{G}}$ and $u_{\mathrm{Bu}}<u_{\mathrm{Bd}}$. This can be explained using the following results (see Lemonnier, 1995): If $u$ represents the relative displacement at the soil-geosynthetic interface (which can be either $u_{\mathrm{F}}, u_{\mathrm{G}}, u_{\mathrm{Bu}}$ or $u_{\mathrm{Bd}}$ ) then one can write: if $L_{\mathrm{u}}$ or $L_{\mathrm{v}}$ increases then $u$ decreases;

- Tensions $T_{\mathrm{A}}, T_{\mathrm{Bu}}$ and $T_{\mathrm{Bd}}$ : Note that tensions $T_{\mathrm{Bj}}(j=\mathrm{u}$ or $\mathrm{d})$ are smaller than tensions $T_{\mathrm{A}}$. This is in concordance with the assumption concerning the location of maximum tensions in the reinforcements. Furthermore, tensions in sheet 2 are the largest;

- Inclinations of the critical tensions: Note that the maximum inclinations $\alpha_{\text {Amax }}$ (which correspond to tensions tangent to the failure surface) are much larger than the critical inclinations $\alpha_{\mathrm{A}}$ (see Table 1 and Fig. 4).

\subsection{Comparative study}

The aim of this study is, on one hand, to show the influence of some parameters on our model and, on the other hand, to compare the results obtained from the present model to those obtained from the original "Displacement method" (Gourc et al., 1986). This latter method ("Cartage" software) allows the determination of the safety factor for a given failure line (no automatic process to find the critical one). Thus, for the comparison with our results, the critical failure line obtained from the present model has been considered for the determination of the safety factor and the corresponding mobilised tensions from "Cartage". It is to be noted that it has been impossible to use all the options of "Cartage" for the modelisation of the membrane. Indeed, with "Cartage", the designer has the choice between three different simplified models of the membrane which are the following: (i) "Small displacements" $(\boldsymbol{S D})$, tension $T_{\mathrm{A}}$ at the failure surface remains horizontal, which is the most conservative; (ii) "Large displacements 1 ", tension $T_{\mathrm{A}}$ is tangent to the failure surface; and (iii) "Large displacements 2" (LD), tension $T_{\mathrm{A}}$ remains horizontal, which is the less conservative. The second modelisation gives results, in terms of safety factor and reinforcement tensions, which lie between those of the other two. 
Only the first (SD) and third (LD) modelisations give results for the considered failure surfaces (log-spirals) and are considered in this section. Indeed, for the second modelisation, problems for the calculation of the normal stress distribution $\sigma(\mathrm{X})$ (see Fig. 1) have occurred. Hence, for the following results obtained from "Cartage", the tensions are assumed to remain horizontal. The three following sections deal with the case study presented in Fig. 4.

\subsubsection{Influence of the vertical displacement on top of the slope $\left(y_{\mathrm{t}}\right)$}

The choice of $y_{\mathrm{t}}$ allows the designer to impose a limitation on the displacements in the structure. Fig. 5a and $\mathrm{b}$ show the influence of $y_{\mathrm{t}}$ on the determination of the safety factor and the reinforcement tensions for the three models (present one, "Cartage" SD and LD), and the inclinations of the tensions are given for the present model. Since the same failure surface (the one obtained from the present model) has been considered for the three models, and their associated safety factors $F_{\mathrm{s} 0}$ corresponding to the unreinforced slope are also the same (0.893), the differences between the $F_{\mathrm{s}}$ values obtained by these models arise only from the determination of the reinforcement tensions.

These two figures show that the variations of $F_{\mathrm{s}}, T_{\mathrm{A} 1}$ and $T_{\mathrm{A} 2}$ versus $y_{\mathrm{t}}$ are similar for these three models, and that "Cartage SD" gives much smaller values than the two others. The following comments may be added:

- Concerning the safety factor (Fig. 5a): (i) The present model gives values very close to those of "Cartage LD", (ii) $F_{\mathrm{s}}$ increases with $y_{\mathrm{t}}$, which is due to the fact that the reinforcements are more utilized for a larger local displacement $y_{1}$ up to a point where the sheet should reach its ultimate strength (not shown on the figures) and (iii) The variations of $F_{\mathrm{s}}$ of all models are quasi rectilinear for $y_{\mathrm{t}}=1-6 \mathrm{~cm}$. The increase of $F_{\mathrm{s}}$ on this interval is about $52.6 \%$ for the present model and the scatter with "Cartage" is in average of $18.8 \%$ for "Cartage SD" and $0.3 \%$ for "Cartage LD";

- Concerning the reinforcement tensions (Fig. 5b): (i) the present model gives values which lie between the two modelisations of "Cartage", (ii) $T_{\mathrm{A} 1}$ and $T_{\mathrm{A} 2}$ increase with $y_{\mathrm{t}}$ and (iii) The scatter with the present model concerning $T_{\mathrm{A} 1}$ is in average of $187 \%$ for "Cartage SD" and $20 \%$ for "Cartage LD" $(91 \%$ and $15 \%$, respectively, for $T_{\mathrm{A} 2}$ ). The scatters between the results obtained from the present model and those from "Cartage LD" are relatively not significant, since the models of the membrane are quite different in the two methods;

- Concerning the tension inclinations (Fig. 5b): As mentioned before, no comparison can be done in terms of inclinations. However, note that the critical inclinations $\alpha_{\mathrm{A} 1}$ and $\alpha_{\mathrm{A} 2}$, as given by the present model, decrease slightly when $y_{\mathrm{t}}$ increases. This can be explained by the fact that the relative displacement $u_{\mathrm{F}}$, which satisfies the displacement compatibility condition, increases with $y_{\mathrm{t}}$ (see Lemonnier, 1995). This term has a major influence on the determination of the reinforcement tensions and their inclinations (see companion paper): Its increase produces the decrease of the critical inclinations.

Finally, note that if a safety factor $F_{\mathrm{s}}$ of 1.5 is required to ensure the wall stability, both the present model and "Cartage LD" give this result for $y_{\mathrm{t}}=6 \mathrm{~cm}$, while "Cartage SD" gives only $F_{\mathrm{s}}=1.15$. 
(a)

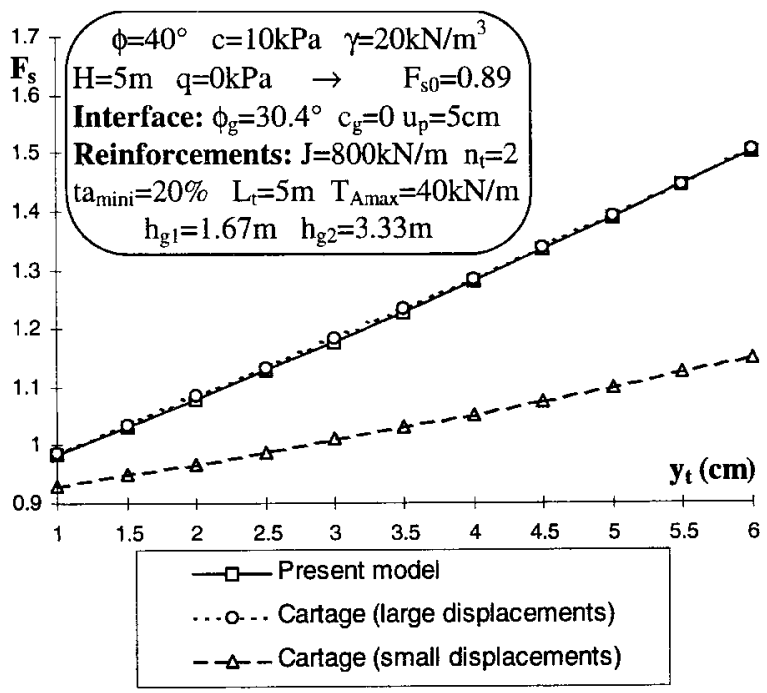

(b)

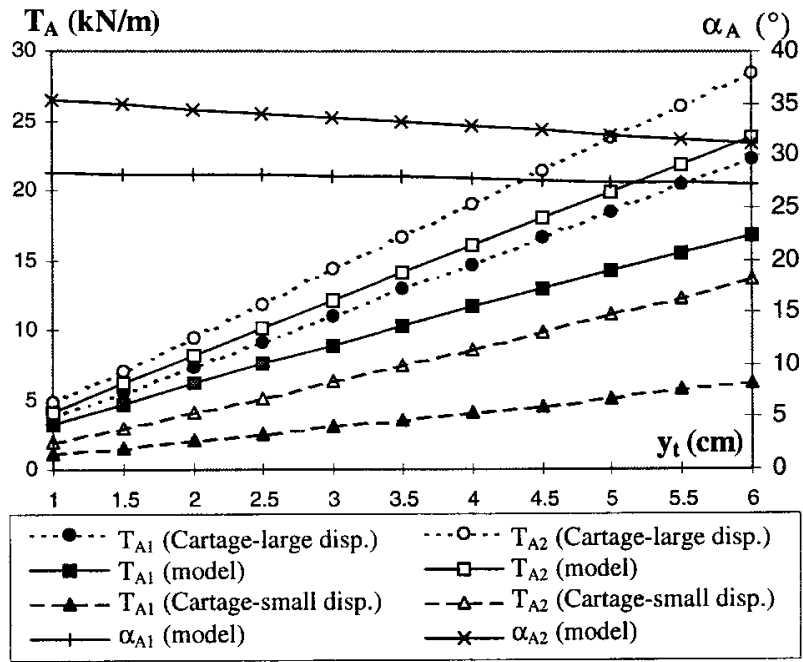

Fig. 5. (a) Influence of $y_{\mathrm{t}}$ on the safety factor. (b) Influence of $y_{\mathrm{t}}$ on the critical tensions and their inclinations.

\subsubsection{Influence of the position of a sheet in the reinforced slope}

Figs (6a and 6b) show the influence of the position $h_{\mathrm{g}}$ of the sheet on the determination of the safety factor, the critical tensions and their inclinations for the case study in Fig. 4 excepted that: (i) only one geosynthetic sheet reinforces the wall, (ii) the depth $h_{\mathrm{g}}$ varies from 0.5 to $4.5 \mathrm{~m}$ and (iii) a vertical top displacement $y_{\mathrm{t}}=4 \mathrm{~cm}$ is selected. 
(a)

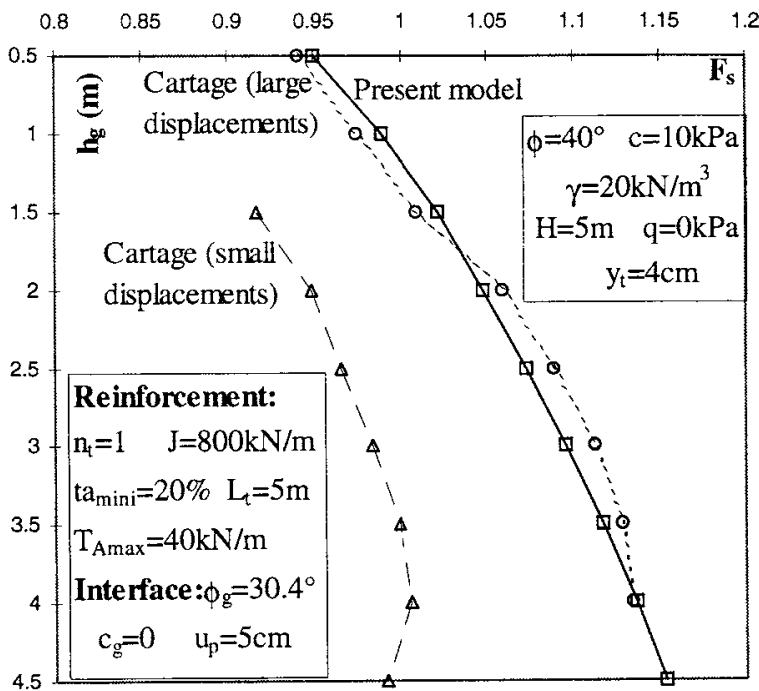

(b)

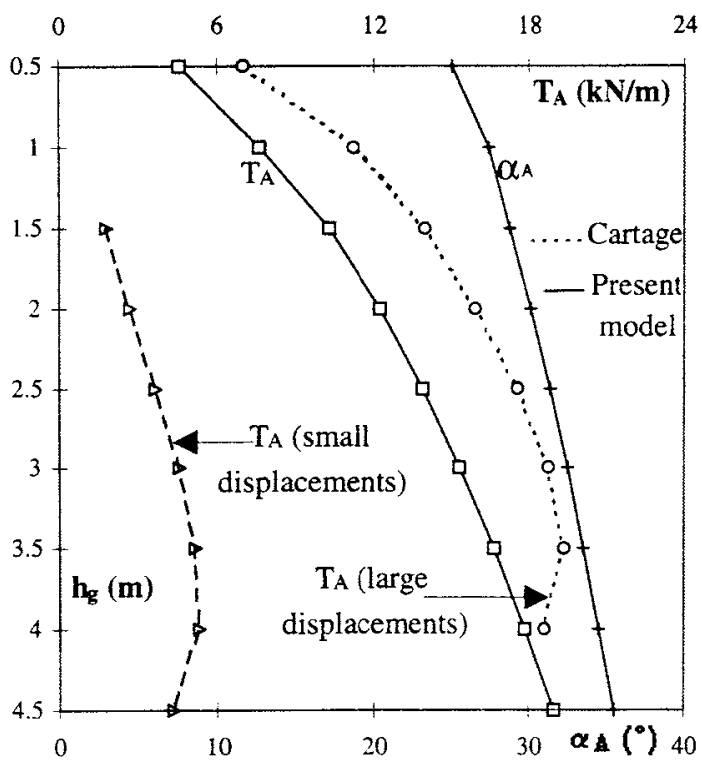

Fig. 6. (a) Influence of $h_{\mathrm{g}}$ on the safety factor. (b) Influence of $h_{\mathrm{g}}$ on the critical tensions and their inclinations.

The variations of $F_{\mathrm{s}}$ and $T_{\mathrm{A}}$ are strictly increasing with $h_{\mathrm{g}}$ for the present model, while they pass through a maximum value for both assumptions of "Cartage" (around $h_{\mathrm{g}}=3.5 \mathrm{~m}$ for LD and $h_{\mathrm{g}}=4 \mathrm{~m}$ for SD).

The following comments may be added: (i) the scatter between the results of the present model and those of "Cartage LD" concerning $F_{\mathrm{s}}$ (Fig. 6a) is not significant 
(about $1.8 \%$ ), (ii) concerning $T_{\mathrm{A}}$ (Fig. 6b), the scatter is larger (around 22\%), and (iii) "Cartage SD" gives much smaller values than the two other models for both $F_{\mathrm{s}}$ and $T_{\mathrm{A}}$. The scatter with the present model is about $12 \%$ for $F_{\mathrm{s}}$ and $137 \%$ for $T_{\mathrm{A}}$.

Finally, concerning the inclination $\alpha_{\mathrm{A}}$ given by the present model (Fig. 6b), it increases significantly (about 42\%) when the depth increases from 0.5 to $4.5 \mathrm{~m}$.

\subsubsection{Influence of the number of reinforcement sheets}

Fig. 7 shows the influence of the number of reinforcement sheets on the determination of the safety factor for the case study in Fig. 4 excepted that the wall is reinforced by one to four geosynthetic sheets, and a top vertical displacement $y_{\mathrm{t}}=4 \mathrm{~cm}$ is selected. The spacing between the reinforcement sheets is constant.

It shows that (i) the variations of $F_{\mathrm{s}}$ are similar for the three models, (ii) the safety factor increases with the number of reinforcing sheets, (iii) the results given by the present model are quite close to those of "Cartage LD" (average scatter of $1.5 \%$ ), and much greater than those of "Cartage SD" (average scatter of 27\%). Note, that for a number of reinforcement sheets greater than 2, the present model gives larger values than "Cartage LD". This is probably due to the fact that the present model allows for the inclination of the reinforcement tensions, and therefore a larger mobilisation of the geosynthetic sheets. The scatters between these two methods are $2 \%$ for three sheets, and $6 \%$ for four sheets.

If a safety factor of 1.5 is required to insure the wall stability, then both the present model and "Cartage LD" give this result for three reinforcement sheets, while "Cartage SD" gives only $F_{\mathrm{s}}=1.15$ in this case.

Finally, Fig. 8 shows the distribution of $T_{\mathrm{A}}$ along the failure surface for the three methods and $\alpha_{A}$ for the present model in the case of four reinforcement sheets. For the

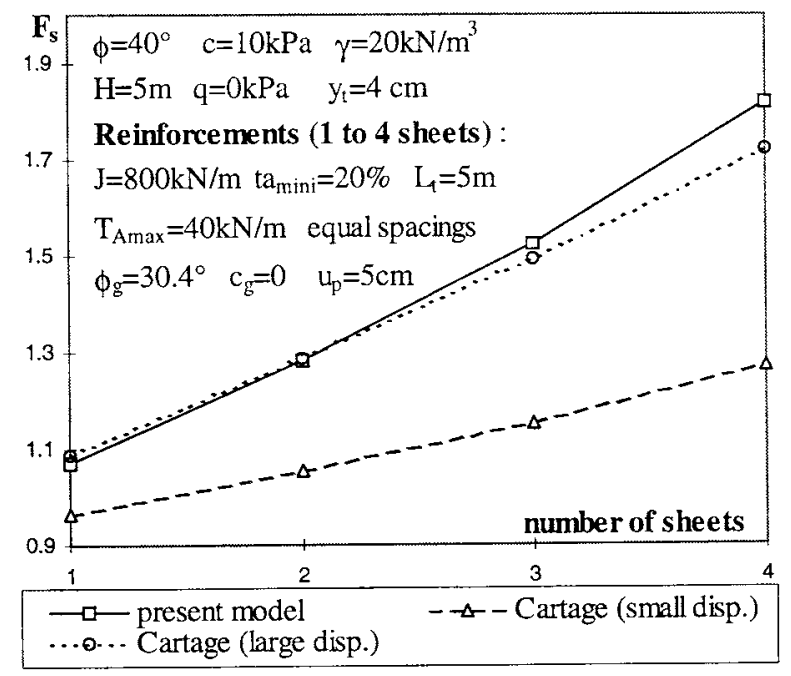

Fig. 7. Influence of the number of sheets on the safety factor. 


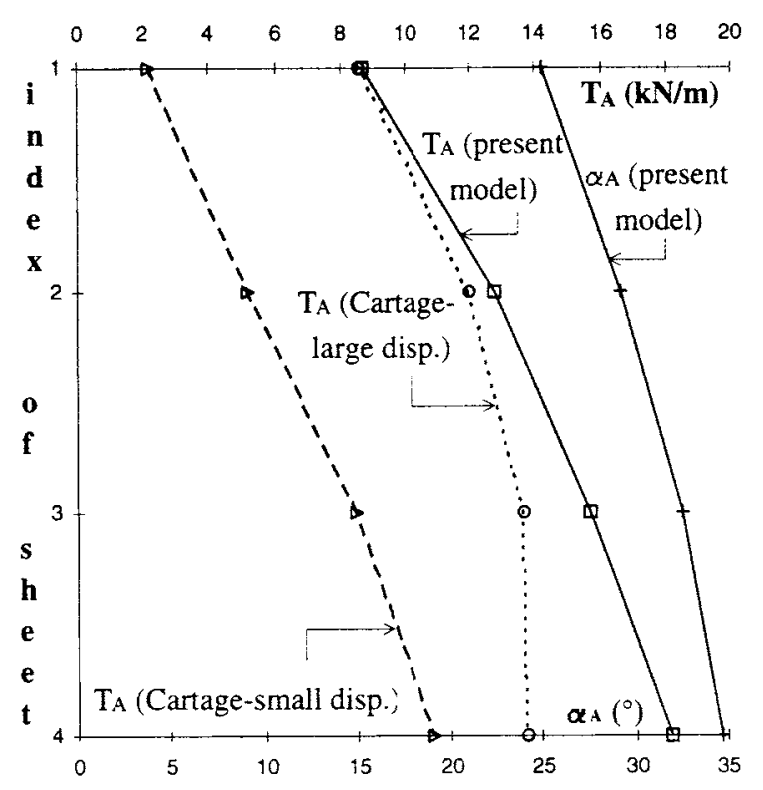

Fig. 8. Distribution of the reinforcement tension along the failure surface case of four reinforcement sheets.

present model, these distributions are very similar to those of Fig. 6b. As in the two previous sections, "Cartage SD" gives much smaller results than those of the two other. Concerning "Cartage LD", $T_{\mathrm{A}}$ is the same as that from the present model for the upper sheet, then the present model gives larger values, and the scatter between the two methods increases with the depth (from 1 to $32 \%$ ).

\section{Conclusion}

A new development of the French "displacement method" for geosynthetically reinforced slope stability analysis has been presented in this paper. The variational limit equilibrium method, which has already been applied with success to the case of unreinforced slopes (Baker and Garber, 1977), has been presently used for the global stability analysis of geosynthetically reinforced slopes. The local stability analysis of the present model, which is performed independently from the global one, is presented in a companion paper (Lemonnier et al., 1998).

The present analysis has shown that the results obtained by Baker and Garber (1977) are still valid in the present case. Indeed, considering a safety factor $F_{\mathrm{s}}$ defined with respect to the shear characteristics of the soil, the critical shape of the failure surface (i.e. the one giving the minimum value of $F_{\mathrm{s}}$ ) is a log-spiral of angle $\phi_{\mathrm{r}}$ (reduced friction angle). Furthermore, the three limit equilibrium equations of the sliding mass are all satisfied, and no assumption has been made concerning the normal stress distribution along the failure surface. 
A computer program has been performed for the implementation of this model. Its use has shown that the model is rather complex from the numerical point of view. It is due to the nonlinearity of the implicit equation in $F_{\mathrm{s}}$, together with discontinuities of some functions occurring in the calculation process. These discontinuities are induced by the consideration of the reinforcement tensions.

A parametric study has been presented in order to show the influence of several geometrical parameters on the analysis in the case of a $5 \mathrm{~m}$ high reinforced vertical wall. The following results have been obtained: The safety factor and the reinforcement tensions, as given by the present model, increase with (i) the vertical displacement at top of the wall; (ii) the depth at which is placed a unique sheet; and $F_{\mathrm{s}}$ increases with (iii) the number of reinforcement sheets.

Finally, the results obtained from the original "displacement method" ("Cartage" Software), which considers a simplified modelisation of the membrane with two different assumptions (small and large displacements, the reinforcement tensions remaining horizontal), have been compared to the present ones. It has shown that the assumption of small displacements gives much smaller values in terms of the safety factor and of the reinforcement tensions, compared to those of the present model and those of "Cartage large displacements". These two latter models give quite the same results in terms of safety factor. Finally, it can be concluded that this comparative study seems to show that the present model (i) is less conservative than the original "displacement method" in the case of the small displacements assumption, and (ii) gives very close results to the ones of the large displacements assumption.

\section{References}

Andrawes, K.Z., McGown, A., Wilson-Fahmy, R.F., Mashhour, M.M., 1982. The finite element method of analysis applied to soil-geotextile systems. Proceedings Second Int. Conf. on Geotextiles, Vienna, Austria, vol. 3, pp. 695-700.

Anthoine, A. (1990) Une méthode pour le dimensionnement à la rupture des ouvrages en sols renforcés. Rev. Franç. Géotech. 50, 5-21

Baker, R., Garber, M., 1977. Variational approach to slope stability. Proceedings 9th International Conference on Soil Mechanics and Foundation Engineering. Tokyo, Japan, vol. 2, pp. 9-12.

Blanchier, A., 1982. Etude de la stabilité d'un talus renforcé par des nappes géotextiles. Thèse: Doct. Ing., Université Claude Bernard-Lyon I, France, 165 p.

Bonaparte, R., Holtz, R.D., Giroud, J.P., 1987. Soil reinforcement design using geotextiles and geogrids. Geotextile Testing and the Design Engineer, ASTM STP 952, pp. 69-116.

Bordairon, M., 1986. Dimensionnement des massifs en sol renforcé par géosynthétiques. Thèse Doct. $3^{\text {eme }}$ cycle. Université Scientifique et Médicale et l'Institut National Polytechnique de Grenoble, $311 \mathrm{p}$.

Broms, B.B., 1978. Design of fabrics reinforced retaining structures. Proceedings of the Symp on Earth Reinforcement. ASCE. Pittsburgh, PA, USA, pp. 282-304.

Collin, J.G., 1986. Earth wall design. PhD thesis, Department of Civil Engineering, University of California, Berkeley, CA, USA, $457 \mathrm{p}$.

Gourc, J.P., Ratel, A., Delmas, Ph., 1986. Design of fabric retaining walls: the Displacements Method. Proceedings Third International Conference on Geotextiles and geomembranes, Vienna, Austria, vol. 2, pp. 289-294.

Hird, C.C., 1986. Stability charts for reinforced embankments on soft ground. Geotextiles and Geomembranes $4,107-127$ 
Ingold, T.S., Miller, K.S., 1984. Design of geotextile reinforced embankments. Proceedings of the Eight Regional Conference for Africa on Soil Mechanics and Foundation Engineering. Harare, pp. 459-464.

Jewell, R.A., 1982. A limit equilibrium design methods for reinforced embankments on soft foundations. Proceedings Second Int. Conf. on Geotextiles. Las Vegas, USA, pp. 671-676.

Kaniraj, S.R., 1994. Rotational stability of unreinforced and reinforced embankments on soft soils. Geotextiles and geomembranes 13 (11) 707-726

Lemonnier, P., 1995. Application de la méthode variationnelle au problème de la stabilité des talus renforcés par des nappes géosynthétiques. Ph.D. thesis. I.N.S.A Lyon, France, 483 p.

Lemonnier, P., Soubra, A.H., Kastner, R., 1998. 'Variational displacement method' for geosynthetically reinforced slope stability analysis: I. Local stability. Geotextiles and Geomembranes 16 (1) 1-25.

Leshchinsky, D., Reinschmidt, A.J. (1985) Stability of membrane reinforced slopes. Journal of Geotechnical Engineering, ASCE 111 (11), 1285-1300

Low, B.K., Wong, K.S., Lim, C., Broms, B.B., 1990. Slip circle analysis of reinforced embankments on soft ground. Geotextile Geomembrane 9, 165-181

McGown, A., Andrawes, K.Z., 1977. The influence of non-woven fabric inclusions on the stress strain behaviour of a soil mass. C.R. Colloid Int. Sols Textiles, Paris, France, pp. 161-166.

Murray, R.T., 1984. Reinforcement techniques in repairing slope failures. Proceedings Polymer grid Reinforcement conference. Thomas Telford Limited, London, pp. 47-53.

Petrov, I.P., 1968. Variational Methods in Optimum Control Theory. Academic Press, New York, 216 p.

Ratel, A., 1987. Modélisation d'un sol renforcé par géosynthétique: application de la méthode en déplacements. Thèse Doct. Ing., Université Scientifique et Médicale et l'Institut National Polytechnique de Grenoble, France, 357 p.

Rowe, R.K., Soderman, K.L., 1985. An approximate method for estimating the stability of geotextilereinforced embankments. Canadian Geotechnical Journal 22, 392-398

Schmertmann, G.R., Chouery-Curtis, V. E., Johnson, R.D., Bonaparte, R., 1987. Design charts for geogrid reinforced soil slopes. Proceedings of the Geosynthetics '87, New Orleans. IFAI, pp. 108-120.

Steward, J.E., Williamson, R., Mohney, J., 1977. Guidelines for use of fabrics in construction and maintenance of low-volume Roads. Earth Reinforcement, USDA, Forest Service, Portland, Oregon, USA. Chapter 5, revised 1983, pp. 87-95 and 102-105. 